\title{
An Improved Dynamic Voltage Restorer Model for Ensuring Fault Ride-Through Capability of DFIG- based Wind Turbine Systems
}

\author{
Musayyibi Shuaibu* and Adamu Saidu Abubakar \\ Department of Electrical Engineering, Ahmadu Bello University Zaria - Nigeria. \\ "Corresponding author: smusayyibi@abu.edu.ng, Tel: +234-8034963420
}

\begin{abstract}
Renewable energy sources (RES) are being integrated to electrical grid to complement the conventional sources in meeting up with global electrical energy demand. Among the RES, Wind Energy Conversion Systems (WECS) have gained global electricity market competitiveness especially the Doubly Fed Induction Generator (DFIG)-based Wind Turbines (WTs) because of flexible regulation of active and reactive power, higher power quality, variable speed operation, four quadrant converter operation and better dynamic performance. Grid connected DFIG-based WTs are prone to disturbances due to faults in the network which made the utilization of the power generated a major concern. The grid code requirement for integrating the DFIGs to grid specified that they must remain connected and support the grid stability during grid disturbances of up to 1500milliseconds. The ability of the DFIG WT system to uphold to the grid codes requirement is termed the Fault Ride Through (FRT). This paper presented a 1.5MW grid connected DFIG-based WT model with a Dynamic Voltage Restorer (DVR) for FRT capability enhancement. The design and simulation were performed in MATLAB/Simulink software. The test system was subjected to disturbances leading to Low Voltage Ride - Through (LVRT), Zero Voltage Ride - Through (ZVRT) and High Voltage Ride - Through (HVRT) considering three - phase balanced fault and single line to ground fault. The performance of improved model of DVR shows enhancement over conventional DVR in terms of voltage compensation and fault current mitigation.
\end{abstract}

Keywords: Doubly Fed Induction Generator, Dynamic Voltage Restorer, Fault Ride - Through, IEEE519 Standard, Wind Energy Conversion System.

(C) 2020 Penerbit UTM Press. All rights reserved

Article History: received 25 December 2019; accepted 15 April 2020; published 25 April 2020.

\section{INTRODUCTION}

Doubly Fed Induction Generator (DFIG) is the most employed generator for Wind Turbine (WT) system due to its advantages such as the reduced mechanical stress on the WT, low power rating of the connected power electronics converters, flexible regulation of active and reactive power, higher power quality and variable speed operation [1-6].

However, the major disadvantage of grid connected DFIG-based WT is that increasing the performance of DFIG by flux weakening control method is very difficult because of the direct connection of the stator to the grid [2]. In this configuration, the stator flux is directly controlled by the grid voltage. Any voltage dip will result in a sudden change of machine magnetization thereby producing a current surge in the Rotor Side Converter (RSC) [7]. This surge current is usually large and without suitable control strategy, it may cause damage to the converters. Hence, appropriate control strategy must be employed to ride through low voltage faults [8].

In order to sustain the grid connected WT systems, wind power grid connection codes which require that WTs should remain connected to the grid for the purpose of maintaining the overall system reliability were enacted [3].
According to grid codes, whenever grid experiences low voltage faults, WT system need to ride through a period of up to $150 \mathrm{~ms}$ and a recovery period of up to $1.35 \mathrm{~seconds}$; and inject up to rated current of the reactive current to the grid during the entire low voltage fault time [8]. The revised grid codes require that WTs must also provide reactive power during the faults [7].

The ability of the WT to stay connected to the grid during grid faults is termed the Fault Ride-Through (FRT) capability [3]. This made it difficult to continue using the crowbar method of protecting the converters from flow of rotor over-currents during faults [1]. Crowbar operation disables and short-circuits the RSC, making the DFIG to act like a Squirrel Cage Induction Generator (SCIG) thereby absorbs reactive power instead of supporting the grid [7].

Other techniques developed in order to address the limitations of using crowbars are the protection using Series Grid Side Converter (GSC), Dynamic Resistor, connection of Static Synchronous Compensator (STATCOM) and Dynamic Voltage Restorer (DVR) at the Point of Common Coupling (PCC) are detailed [1, 7, 9, 10]. However, STATCOM operation cannot meet up with fast variations in voltage source and as such it cannot 
protect the RSC from over current and therefore require the addition of crowbar protection $[1,11]$.

The use of DVR provide a better solution as it does not require protective circuit during operation. DVR have shown effectiveness in restoring quality of voltage at load side when the voltage at source terminals is disturbed [1]. Figure 1 shows the basic components and placement between the DFIG - Based WT and the grid at PCC. Several techniques were developed for control of DVR such as missing voltage technique, Enumerated MPCbased control, Hysteresis control, Discrete state space control and Real-time control [9, 12-16]. Despite its effectiveness, DVR is prone to damage by large grid side fault current [17].

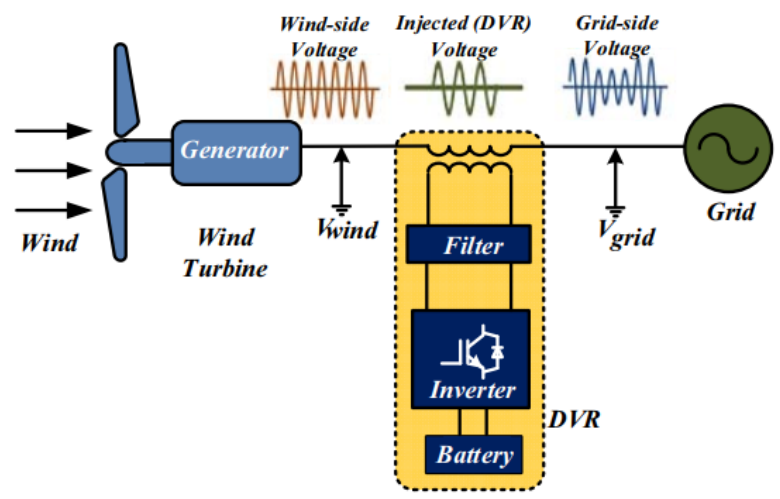

Figure 1. Topology of DVR in Grid Connected DFIGBased WT System

In this paper, a DVR with Proportional Resonant (PR) current controller and active damping loop were implemented to detect and activate the fault current limiting control scheme in addition to the voltage compensation function. The measurements of current for mitigation was achieved using Multiple Second - Order Generalized Integrators PLL (MSOGI-PLL) because of its fast response and less computational burden.

\section{CONCEPTS OF DFIG AND DVR}

The concepts of modelling and operation of DFIG and DVR are discussed in this section.

\subsection{Model of a DFIG}

The dynamic model of DFIG is based on the generalized machine model in synchronous reference frame and all the system parameters and variables in per unit ( $\mathrm{pu})$ as referred to the stator side [18]. Figure 2 shows the equivalent circuit of the DFIG in synchronous dq reference frame.

The dq voltage, current and flux equations of the equivalent circuit of DFIG are as follows [1]:

$$
\begin{aligned}
& v_{d s}=R_{s} i_{d s}+\frac{d \lambda_{d s}}{d t}-\omega_{e} \lambda_{q s} \\
& v_{q s}=R_{s} i_{q s}+\frac{d \lambda_{q s}}{d t}+\omega_{e} \lambda_{d s} \\
& v_{d r}=R_{r} i_{d r}+\frac{d \lambda_{d r}}{d t}-\left(\omega_{e}-\omega_{r}\right) \lambda_{q r} \\
& v_{q r}=R_{r} i_{q r}+\frac{d \lambda_{q r}}{d t}+\left(\omega_{e}-\omega_{r}\right) \lambda_{d r}
\end{aligned}
$$

Where $v_{d s}$ and $v_{q s}$ are dq stator voltages, $v_{d r}$ and $v_{q r}$ are dq rotor voltages; $i_{d s}$ and $i_{q s}$ are dq stator currents, $i_{d r}$ and $i_{q r}$ are dq rotor currents; $\omega_{e}$ is the supply angular frequency and $\omega_{r}$ is the rotor angular frequency; $\lambda_{d s}$ and $\lambda_{q s}$ are the $\mathrm{dq}$ stator flux linkages, $\lambda_{d r}$ and $\lambda_{q r}$ are the dq rotor flux linkages. $R_{s}$ and $R_{r}$ are the stator and rotor resistance respectively.

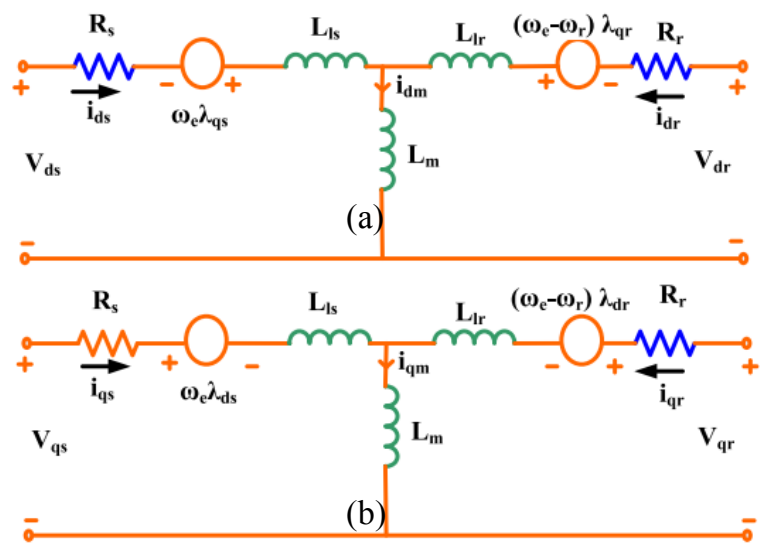

Figure 2. Equivalent Circuit of DFIG [19]

If $L_{s}$ and $L_{r}$ represent the stator and rotor inductance respectively, then the stator and rotor side inductances can be obtained using:

$$
\begin{aligned}
& L_{s}=L_{l s}+L_{m} \\
& L_{r}=L_{l r}+L_{m}
\end{aligned}
$$

Where $\mathrm{L}_{l s}$ and $\mathrm{L}_{l r}$ are the stator and rotor leakage inductance respectively and $\mathrm{L}_{\mathrm{m}}$ is the magnetizing inductance. The flux linkage equation for both stator and rotor are given by

$$
\begin{aligned}
& \lambda_{d s}=L_{s} i_{d s}+L_{m} i_{d r} \\
& \lambda_{q s}=L_{s} i_{q s}+L_{m} i_{q r} \\
& \lambda_{d r}=L_{m} i_{d s}+L_{r} i_{d r} \\
& \lambda_{q r}=L_{m} i_{q s}+L_{r} i_{q r}
\end{aligned}
$$

The real power $\left(P_{S}\right)$ and reactive power $\left(Q_{S}\right)$ generated by DFIG are given by

$$
\begin{aligned}
& P_{s}=\frac{3}{2}\left(v_{q s} i_{q s}+v_{d s} i_{d s}\right) \\
& Q_{s}=\frac{3}{2}\left(v_{q s} i_{d s}-v_{d s} i_{q s}\right)
\end{aligned}
$$

\subsubsection{Operating Principle of DFIG}

The analysis of DFIG operation during steady - state and transient conditions is vital to understanding its behavior during grid faults. The fault analysis is necessary for the implementation of FRT capability [1].

The stator of DFIG is connected directly to the grid while the rotor is connected to the grid via slip rings through a partial-scale back-to-back power converter. The back-to-back converter has a Rotor Side Converter (RSC) and Grid Side Converter (GSC) connected by a dc-link. The dc-link is a capacitor serving as energy storage and also serving as dc-link voltage variations or ripples limiter. The converter handles about $20-30 \%$ of total generated power and also controls torque, speed and reactive power 
from or to the grid [20]. The rotor three-phase windings are energized with three-phase currents which is supplied by the RSC. As a result of that, rotor magnetic field interacts with stator magnetic field to develop torque which is a vector product of the two vector fields [21].

\subsubsection{Behavior of DFIG during Grid Fault}

The stator flux $\left(\lambda_{s}\right)$ rotates at constant magnitude proportional to the grid voltage and at synchronous speed $\left(N_{s}\right)$ during normal operation. Occurrence of grid fault drops voltage extremely at the generator terminal due to the direct connection of stator winding to the grid. According to the constant flux leakage principle, the stator flux cannot react to the voltage drop instantly [10]. Consequently, dc voltages are produced in the stator windings. The dc component of stator voltage is proportional to the severity of the fault. This de voltage component of the stator changes the slip of the DFIG to about $20 \%[10,22]$.

The voltage drop reduces active power generation which can lead to rapid increase in the rotor current in order to compensate the active power by the rotor side converter (RSC). Hence, the converter increases the rotor voltage and an overvoltage in the DC-link. However, the maximum values of rotor current and dc-link voltage are critical to guarantee effective FRT capability [1].

Figure 3 illustrates the dynamic behavior of stator flux during fault. It can be deduced from the figure that the flux vector;

i. Rotates about outer circle during normal operations.

ii. Split into two - the dc component about OO' and ac synchronous component AO'.

iii. The ac component offsets the dc part and decay naturally along point $\mathrm{B}$ immediately after the fault, [20].

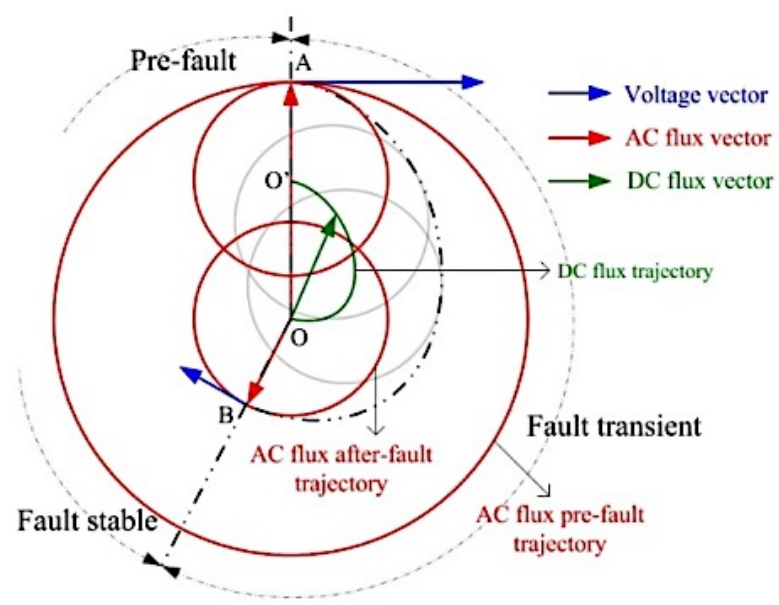

Figure 3. Stator Flux Trajectory during Fault [20]

The inrush current in rotor due to the fault increases the active power and increase the dc-link capacitor voltage. These lead to dangerous pulsating electromagnetic torque oscillation and finally damage the DFIG [22]. The grid code requirement for the integration of DFIG - Based WT systems is depicted in Figure 4.

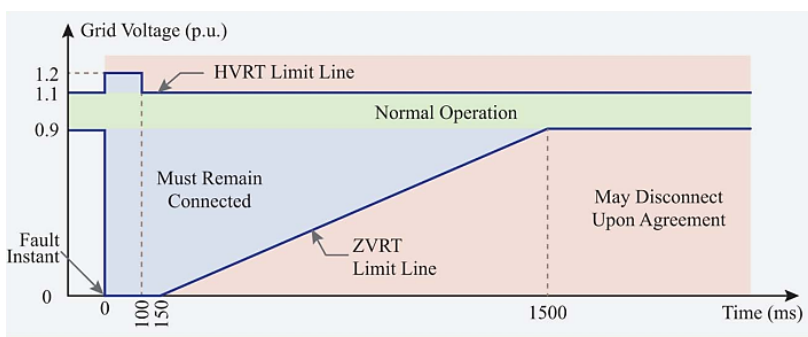

Figure 4. Grid Codes According to E.ON

\subsection{Model of DVR}

The essential components of DVR are the Series injection transformer, the Voltage Source Inverter (VSI), filter and Storage as shown in Figure 5. The power rating of the DVR is given by

$$
S_{D V R}=\sum_{k=a, b, c} V_{i, k}^{r e f} * I_{L}
$$

Where $V_{i}$ is the three - phase AC voltage from the VSI.

The series injection transformer turn ratio is $1: 1$ for coupling of the VSI and grid through filter. The transformer also serves to isolate the VSI from grid. The positive, negative and zero sequence equations are respectively given by:

$$
\begin{aligned}
& v_{1}=\frac{1}{3}\left(v_{a}+a v_{b}+a^{2} v_{c}\right) \\
& v_{2}=\frac{1}{3}\left(v_{a}+a^{2} v_{b}+a v_{c}\right) \\
& v_{0}=\frac{1}{3}\left(v_{a}+v_{b}+v_{c}\right)
\end{aligned}
$$

Where $a=e^{j 2 \pi / 3}$ and $v_{a}, v_{b}, v_{c}$ are the three phase voltages.

Also, the AC output voltages of the VSC are given by:

$$
\begin{aligned}
& v_{i a}=\frac{\sqrt{3}}{2} k m_{a} v_{d} \sin (\omega t+\delta) \\
& v_{i b}=\frac{\sqrt{3}}{2} k m_{a} v_{d} \sin \left(\omega t+\delta-\frac{2 \pi}{3}\right) \\
& v_{i c}=\frac{\sqrt{3}}{2} k m_{a} v_{d} \sin \left(\omega t+\delta+\frac{2 \pi}{3}\right)
\end{aligned}
$$

Where $v_{d}$ is the voltage across the dc - link capacitor, $k$ is the series injection transformer turn ratio and $m_{a}$ is the PWM amplitude modulation ratio.

The active power exchange between the DVR and grid is given by

$$
\begin{aligned}
& P_{D V R}=P_{g}-P_{D F I G} \\
& P_{D V R}=\sum_{k=a, b, c} V_{i, k}^{r e f} * I_{L} \cos \psi-3 V_{L} * I_{L} \cos \psi
\end{aligned}
$$

The phase angle of the injected voltage is the same as the grid voltage. 


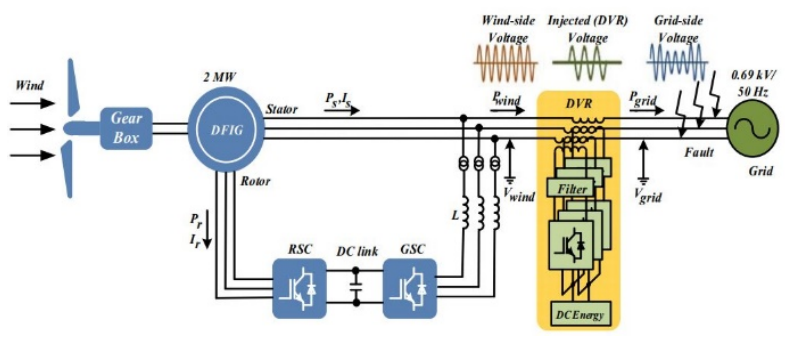

Figure 5. Model of a Grid Connected DFIG - Based WT with DVR

\subsection{PERFORMANCE RESULTS}

In this section, the detailed simulation results obtained for the developed model of wind turbine system with DVR and the performance of the DVR in ensuring FRT of the 1.5MW WT system were presented. The simulation was undertaken during balanced and unbalanced fault conditions without any compensation device, then with DVR in MATLAB/Simulink.

\subsection{Three Phase Balanced Fault}

The test system of DFIG - Based WT was subjected to three - phase balanced fault at interval of $0.4-0.6 \mathrm{~s}$ with fault resistance of $0.0001 \Omega$. The waveforms of the supply voltage and current were presented in Figure 6.
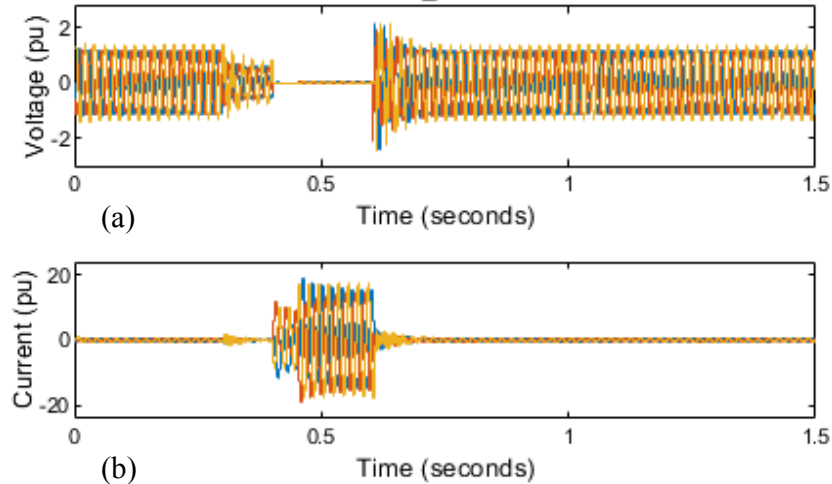

Figure 6. Voltage and Current Waveforms during 3 Phase Balanced Fault without Compensation

The supply voltage is given by Figure 6 (a) while the current is depicted in Figure 6(b). The THD of voltage waveform is $48.75 \%$ while that of current is $187.65 \%$. Figure 7 shows the performance of DFIG under the balanced fault where (a) depicts the EM torque, (b) shows the rotor speed, (c) is for rotor current and (d) is dc - link voltage.

In order to address the issues highlighted with DFIG under the balanced fault, DVR was placed to compensate the voltage deviations and improve the FRT capability. The voltage LVRT, ZVRT and HVRT were normalized as shown in Figure 8 (a) and the harmonic analysis gives an improvement in THD from $48.75 \%$ to $4.01 \%$. Similarly, the current waveform in Figure 8(b) shows how the fault current was reduced $4.0 \mathrm{pu}$ during the severe distortion. The THD for the current is this case was estimated to be $5.55 \%$. (a)

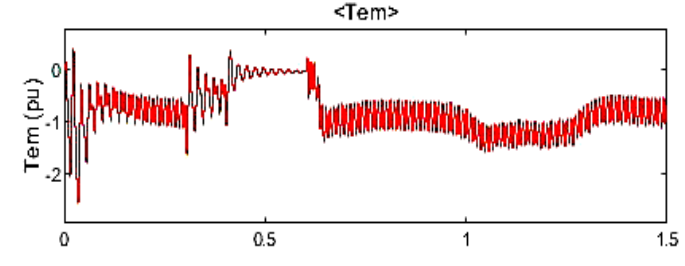

(b)

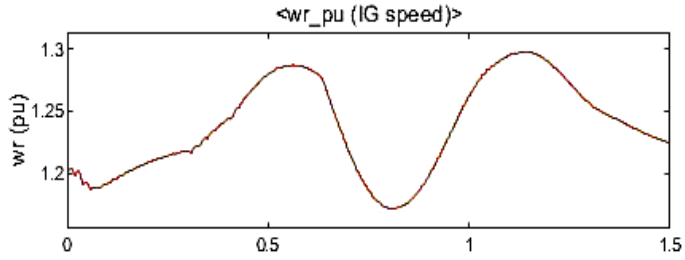

(c)

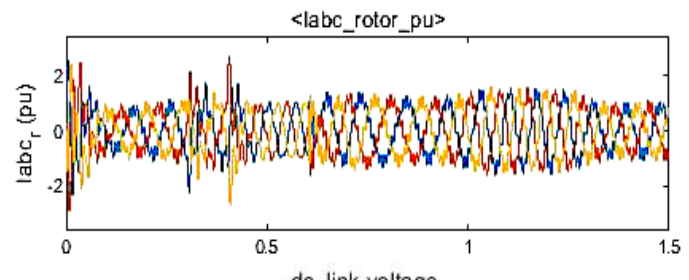

(d)

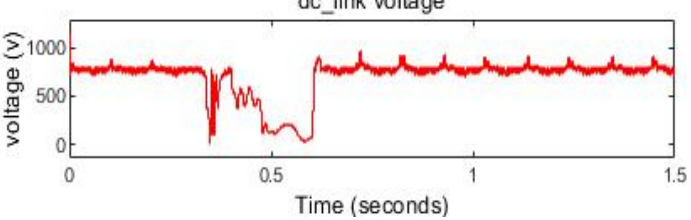

Figure 7. Parameters of DFIG WT System during Balanced Fault

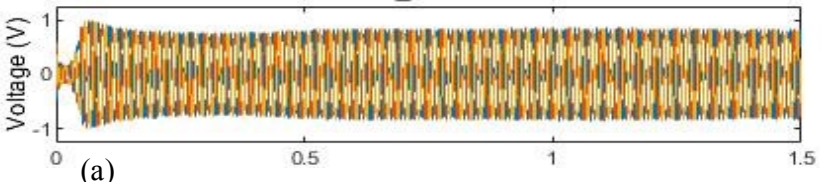

(a)

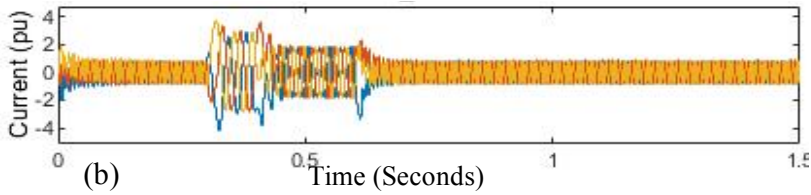

Figure 8. Output Voltage and Current Waveforms after DVR Placement

Figure 9 presented the DFIG WT System parameters - (a) EM torque, (b) rotor speed, (c) rotor current and (d) dc link voltage. The distortion in EM torque was reduced as compared to that of Figure 7(a). The minimum value of rotor speed was $1.2 \mathrm{pu}$ while the rotor current oscillates between $0.3 \mathrm{~s}$ to $0.5 \mathrm{~s}$. This oscillation is translated into sudden dip in $\mathrm{dc}-$ link voltage at same interval. The values of the rotor current during the fault violates the requirement of maximum value to be $2 *$ normal operation. Likewise, the dc - link voltage goes below the minimum value of $1.25 *$ normal operational value.

\subsection{Single Phase to Ground (Unbalanced) Fault}

The performance of DFIG - Based WT when subjected to unbalanced fault at same interval as in the cases of balanced faults was presented in Figure 10. The fault is affected by phase A (blue - phase) while the two other phases maintained normal operation as indicated by the voltage and current waveforms. The LVRT at $0.3 \mathrm{~s}$ was as 
a result of introducing a highly inductive load. Similarly, introduction of capacitive load at $0.6 \mathrm{~s}$ gave rise to the HVRT as show in Figure 10(a) while the fault current in the faulty line (phase A) rose to about $17 \mathrm{pu}$ during the operation (Figure 10(b)). The THD for voltage and current are $29.93 \%$ and $131.43 \%$ respectively.

(a)

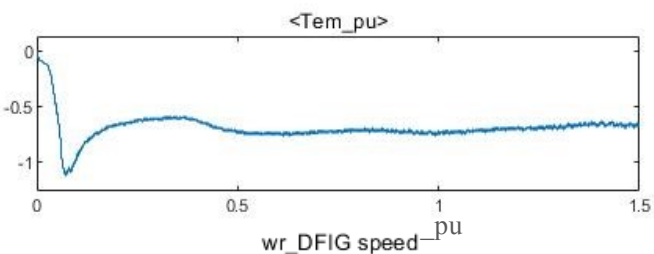

(b)

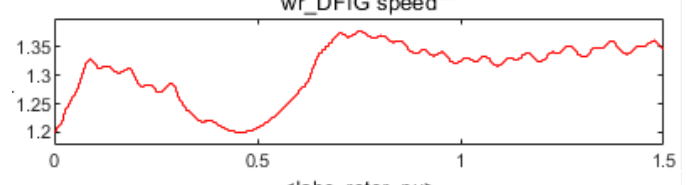

(c)

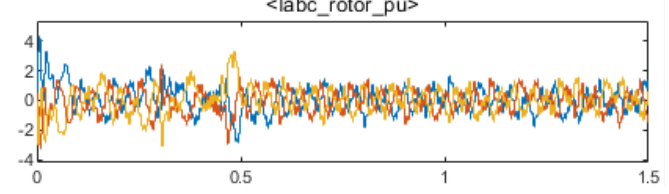

(d)

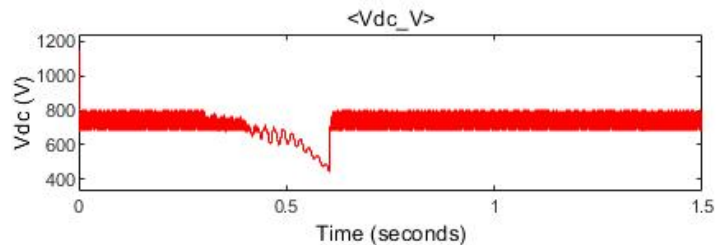

Figure 9. Parameters of DFIG WT System after the DVR Placement
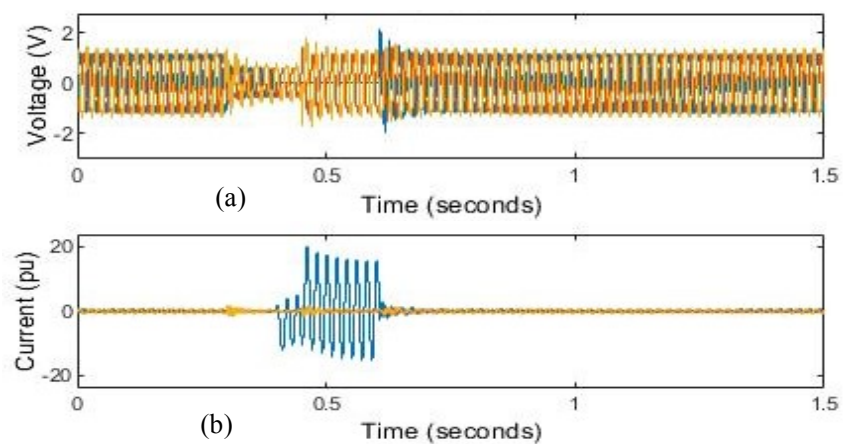

Figure 10. Voltage and Current Waveforms during an Unbalanced Fault (single phase to ground)

The DFIG EM torque, rotor speed, rotor current and dc link voltage are presented in Figure 11. The graphs show similar trend in distortion of rotor current and dc - link voltage compared to the previous cases of balanced faults.

The compensation by DVR shows an improvement on the overall performance of DFIG - Based WT as depicted in Figure 12. The voltage at the stator windings terminal was restored to $0.92 \mathrm{pu}$ with THD of $4.10 \%$ and the output current to the grid during fault operation was also reduced to 4.0 pu with THD of $7.89 \%$.

The spikes in current waveform at $0.3 \mathrm{~s}$ to $0.6 \mathrm{~s}$ shows the effect of fault current in any of the three phases on the others. The distortion in the EM torque when no compensation device was used is now reduced as shown in Figure 13(a). Similarly, the graphs of rotor speed and rotor current show improvement in performance with DVR. The dc - link voltage fluctuations were mitigated at the beginning of fault period. However, the minimum value recorded was below the acceptable limit.
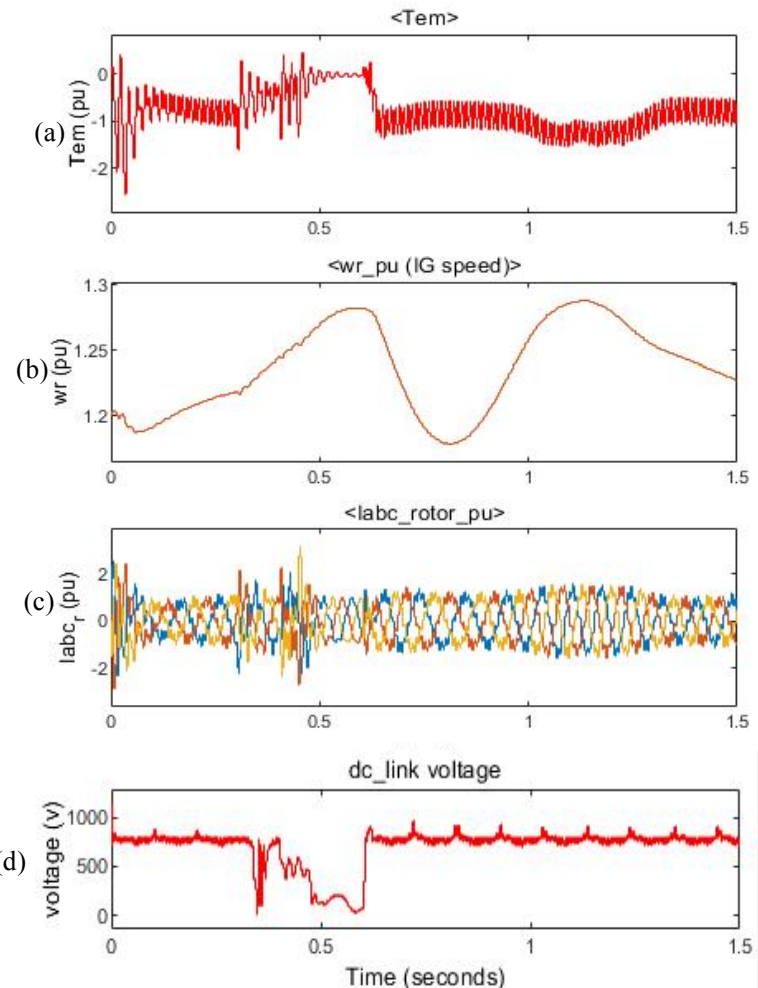

Figure 11. Parameters of DFIG WT System during Unbalanced Fault without Compensation Device

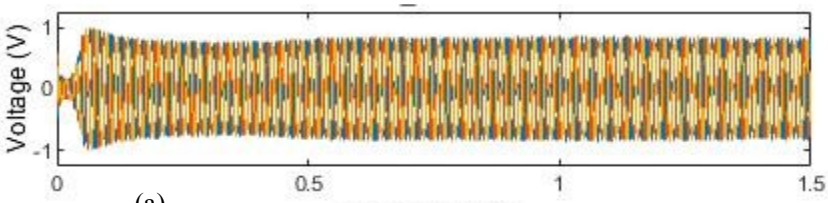

(a)

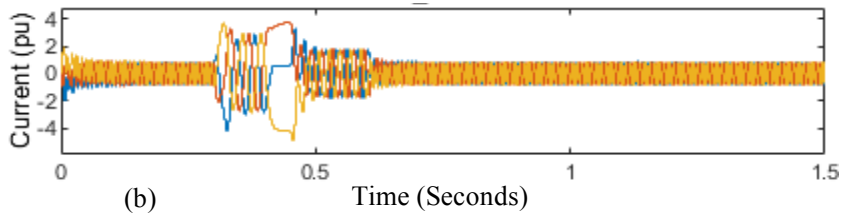

Figure 12. Voltage and Current Waveforms of DFIG Based WT with DVR under Unbalanced Fault.

\subsection{CONCLUSION}

This paper presented an improved model of Dynamic Voltage Restorer (DVR) for Doubly-Fed Induction Generator (DFIG) based Wind Turbine (WT) system. The developed model demonstrated a fault current limiting capability in addition to compensation of voltage sag/swell due to grid faults. The research was focused on improvement of Fault Ride-Through (FRT) capability of DFIG based WT thereby upholding the stringent grid code requirements for the integration of wind turbines to grid networks. The model also ensured the protection of the converters from damages due to short-circuit currents.

Also, The THD of supply voltage in all cases are below 5\% which signifies the compliance with IEEE519 for harmonics content in power supplies. 

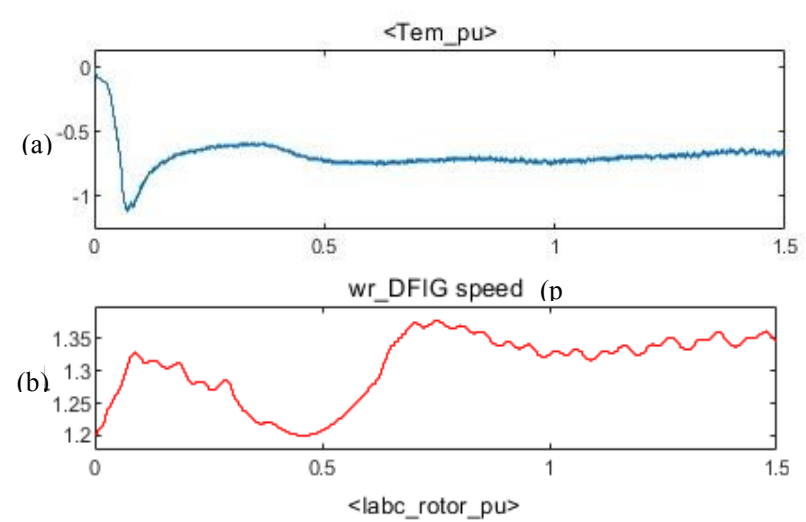

(c)

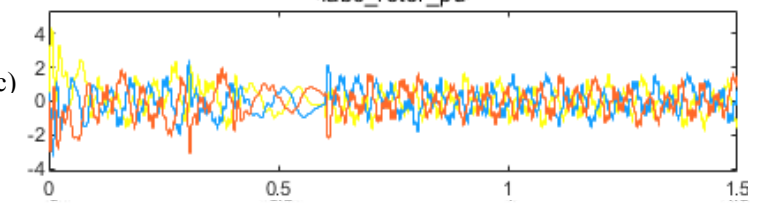

$\langle\mathrm{Vdc}$ V $>$

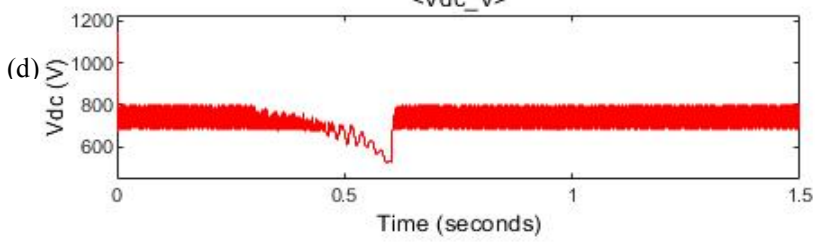

Figure 13. Parameters of DFIG WT System with DVR under Unbalanced Fault

\section{REFERENCES}

[1] R. A. J. Amalorpavaraj, P. Kaliannan, S. Padmanaban, U. Subramaniam, and V. K. Ramachandaramurthy, "Improved fault ride through capability in dfig based wind turbines using dynamic voltage restorer with combined feed-forward and feed-back control," IEEE Access, vol. 5, pp. 2049420503, 2017.

[2] N. Karakasis, E. Tsioumas, N. Jabbour, A. M. Bazzi, and C. Mademlis, "Optimal Efficiency Control in a Wind System with Doubly Fed Induction Generator," IEEE Transactions on Power Electronics, 2018.

[3] L. Yang, Z. Xu, J. Ostergaard, Z. Y. Dong, and K. P. Wong, "Advanced control strategy of DFIG wind turbines for power system fault ride through," IEEE Transactions on power systems, vol. 27, pp. 713-722, 2012.

[4] P. Gardner, G. Andrew, F. H. Lars, M. Colin, and Z. Arthouros, Wind energy-the facts: a guide to the technology, economics and future of wind power: Routledge, 2012.

[5] V. Yaramasu, B. Wu, P. C. Sen, S. Kouro, and M. Narimani, "High-power wind energy conversion systems: State-of-the-art and emerging technologies," Proceedings of the IEEE, vol. 103, pp. 740-788, 2015.

[6] A. F. Shehu, A. S. Abubakar, S. Musayyibi, and K. Idris, "Doubly fed Induction Generator Based Wind Energy Conversion System: A Review," Journal of Science Technology and Education, vol. 7, pp. 145150, 2019.

[7] D. Zhu, X. Zou, L. Deng, Q. Huang, S. Zhou, and Y. Kang, "Inductance-emulating control for DFIGbased wind turbine to ride-through grid faults," IEEE
Transactions on Power Electronics, vol. 32, pp. 8514-8525, 2017.

[8] T. Long, S. Shao, P. Malliband, E. Abdi, and R. A. McMahon, "Crowbarless fault ride-through of the brushless doubly fed induction generator in a wind turbine under symmetrical voltage dips," IEEE Transactions on Industrial Electronics, vol. 60, pp. 2833-2841, 2013.

[9] C. Wessels, F. Gebhardt, and F. W. Fuchs, "Fault ride-through of a DFIG wind turbine using a dynamic voltage restorer during symmetrical and asymmetrical grid faults," IEEE Transactions on Power Electronics, vol. 26, pp. 807-815, 2011.

[10] B. B. Ambati, P. Kanjiya, and V. Khadkikar, "A low component count series voltage compensation scheme for DFIG WTs to enhance fault ride-through capability," IEEE Transactions on Energy Conversion, vol. 30, pp. 208-217, 2015.

[11] K. Padiyar, FACTS controllers in power transmission and distribution: New Age International, 2007.

[12] A. Kazemi and A. Azhdast, "Implementation of a control strategy for dynamic voltage restorer (DVR) and dynamic voltage compensator (DVC)," in Power Systems Conference and Exposition, 2009. PSCE'09. IEEE/PES, 2009, pp. 1-6.

[13] N. Ganesh and P. U. Rani, "Fault-Ride Through of a DFIG Wind Turbine using a Dynamic Voltage Restorer during Symmetrical and Asymmetrical Grid Faults," vol. 1, pp. 2320-8945, 2013.

[14] A. O. Ibrahim, T. H. Nguyen, D.-C. Lee, and S.-C. Kim, "A fault ride-through technique of DFIG wind turbine systems using dynamic voltage restorers," IEEE transactions on energy conversion, vol. 26, pp. 871-882, 2011.

[15] M. İnci, M. Büyük, A. Tan, K. Ç. Bayındır, and M. Tümay, "MVT controlled voltage restorer for faultride through capability," in Electrical and Electronics Engineering (ELECO), 2017 10th International Conference on, 2017, pp. 380-385.

[16] A. V. Ital and S. A. Borakhade, "Compensation of voltage sags and swells by using Dynamic Voltage Restorer (DVR)," in Electrical, Electronics, and Optimization Techniques (ICEEOT), International Conference on, 2016, pp. 1515-1519.

[17] F. Jiang, C. Tu, Q. Guo, Z. Shuai, X. He, and J. He, "Dual-Functional Dynamic Voltage Restorer to Limit Fault Current," IEEE Transactions on Industrial Electronics, 2018.

[18] M. Rahimi and M. Parniani, "Efficient control scheme of wind turbines with doubly fed induction generators for low-voltage ride-through capability enhancement," IET Renewable Power Generation, vol. 4, pp. 242-252, 2010.

[19] S. Alaraifi, A. Moawwad, M. S. El Moursi, and V. Khadkikar, "Voltage booster schemes for fault ridethrough enhancement of variable speed wind turbines," IEEE Transactions on Sustainable Energy, vol. 4, pp. 1071-1081, 2013.

[20] Y. M. Alsmadi, L. Xu, F. Blaabjerg, A. P. Ortega, A. Y. Abdelaziz, A. Wang, et al., "Detailed Investigation and Performance Improvement of the Dynamic Behavior of Grid-Connected DFIG-Based 
Wind Turbines under LVRT Conditions," IEEE Transactions on Industry Applications, 2018.

[21] J. Fletcher and J. Yang, "Introduction to the doublyfed induction generator for wind power applications," in Paths to sustainable energy, ed: InTech, 2010.
[22] R. Sitharthan, C. Sundarabalan, K. Devabalaji, S. K. Nataraj, and M. Karthikeyan, "Improved fault ride through capability of DFIG-wind turbines using customized dynamic voltage restorer," Sustainable Cities and Society, vol. 39, pp. 114-125, 2018. 